\title{
Perfiles políticos en Twitter: el uso electoral del término educación
}

\author{
Political profiles on Twitter: the electoral use of the word education.
}

\section{Joan M. Oleaque Moreno}

Universidad Internacional de Valencia (VIU)

Juanmanuel.oleaque@campusviu.es

Fecha presentación: 26/11/2018| Aceptación: 10/12/2018 |Publicación: 21/12/2018

\section{Resumen}

Este trabajo analiza los perfiles en Twitter de importantes partidos políticos que concurrían a las elecciones generales del 26 de junio de 2016. La exportación de datos toma los últimos 3200 tuits de cada cuenta. Los objetivos del estudio persiguen, inicialmente, revisar la estructura discursiva de los tuits publicados por las cuentas de los partidos (PP, PSOE, Ciudadanos, Podemos e IU) en unas elecciones es en las que se consolidaba el uso político español de esa red social. Por otra, pretenden determinar cuál es el uso cualitativo que estos perfiles le dan al término educación, un concepto de gran relevancia en unas elecciones generales en las que se vinculaba a la necesidad de innovación, a las regulares protestas contra la LOMCE y al rechazo continuo a largos tiempos de recortes. Se aplica el análisis crítico del discurso (ACD) sobre una muestra de 20 tuits de entre los 339 que utilizan de modo destacado este término, para determinar los significados discursivos que subyacen en estos tuits. Los principales resultados indican una utilización del término más ligada al personalismo de los líderes y a unos intereses electorales determinados que a un uso social o a la difusión de los planes políticos sobre materia educativa. Emergiendo, además, determinadas intenciones ideológicas que no resultaban evidentes en la lectura superficial de estos mensajes de Twitter.

Palabras clave: Twitter; Redes sociales; Educación; Partidos Políticos; Elecciones generales; Análisis crítico del discurso.

\section{Resum}

Aquest treball analitza els perfils en Twitter d'importants partits polítics que concorrien a les eleccions generals espanyoles del 26 de juny en 2016. L'exportació de dades pren els últims 3200 tuits de cada compte. Els objectius de l'estudi persegueixen, inicialment, revisar l'estructura discursiva dels tuits publicats pels comptes dels partits (PP, PSOE, Ciutadans, Podemos i IU) en unes eleccions és en les quals es consolidava l'ús polític espanyol d'aqueixa xarxa social. Per una altra, pretenen determinar quin és l'ús qualitatiu que aquests perfils li donen al terme educació, un concepte de gran rellevància en unes eleccions generals en les quals es vinculava a la necessitat d'innovació, a les regulars protestes contra la LOMCE i al rebuig continu front a llarg temps de retallades econòmiques. S'aplica l'anàlisi crítica del discurs (ACD) sobre una mostra de 20 tuits dels 339 que utilitzen de manera destacada aquest terme, per a determinar els significats discursius que subjauen. Els principals resultats indiquen una utilització del terme educació més lligada al personalisme dels líders i a uns interessos electorals determinats que no a un ús social o a la difusió dels plans polítics sobre matèria educativa, emergint, a més, determinades intencions ideològiques que no resultaven evidents en la lectura superficial d'aquests missatges.

Paraules clau: Twitter; Xarxes socials; Educació; Partits Polítics; Eleccions generals; Anàlisi crítica del discurs.

\section{Abstract}

This paper analyses outstanding political parties' Twitter profiles that contested the Spanish general elections in 26th June, 2016. The compilation of data takes the last 3,200 tweets from each account. The objectives of the study seek, on the one hand to review the discursive structure of the tweets published by the parties' accounts (PP, PSOE, Ciudadanos, Podemos and IU); on the other hand, the objectives try to determine what the qualitative use that these political profiles give to the term education is, a relevant concept in general elections of 2016, when it was linked to the need for innovation, to the regular protests against the Organic Law on Education (LOMCE), and to the long-term rejection of budget cuts. Critical Discourse Analysis (CDA) is applied to a sample of 20 tweets from among the 339 tweets that use this term prominently to determine the discursive meanings that underlie in these messages. The main results indicate a use of the term which is more linked to the political leaders' personalities and to electoral interests than to a social use 
Oleaque Moreno, J. M. (2018). Perfiles políticos en Twitter: el uso electoral del término educación. @tic revista d'innovació educativa, 21, 23-30.

or to the dissemination of political programmes. At the same time, ideological meanings that are not evident on the textual surface emerge with this deeper analysis.

Key Words: Twitter; Social networks; Education; Political parties; General elections; Critical Discourse Analysis.

Este artículo forma parte del Proyecto PRODIS-NET: Procesos discursivos en internet: confluencia de partidos, medios y ciudadanos, Ref. FFI2015-67668-R, financiado por MINECO/FEDER.

\section{Introducción}

Este estudio se integra en un proyecto que contempla cómo se construye discursivamente la subjetividad política en España en la red social Twitter. En el presente artículo, se ofrecen diferentes resultados referidos a la revisión de la estructura discursiva que da forma a los mensajes publicados en la red social por los partidos políticos. Y, a cómo, a través de esa estructura, aparece reflejado uno de sus grandes campos temáticos electorales más básicos y transversales, como es el de la educación, especialmente a través de un elemento tan innovador como es el de las redes sociales.

La comunicación política se ha abocado, de hecho, a las redes sociales. Los candidatos relevantes fueron apostando por Facebook o Twitter para darse a conocer de un modo más metódico y paulatino, y más directo, a través de canales sobre los que los políticos tuvieran una mayor sensación de control sobre lo que se emitía, dado que es un medio que facilita la desintermediación, y por tanto, la potencial conexión directa con el simpatizante, o el potencial votante. La sofisticación progresiva de las campañas electorales digitales ha supuesto un nuevo salto comunicacional (Dader, 2017). De tal manera que la gestión comunicativa de la campaña digital, y muy especialmente la gestión de las redes sociales, se convierte en nueva esencia de los procesos discursivos electorales. El comienzo del uso intensivo de las redes sociales en la esfera política tiene su origen tras la exitosa ciber-campaña de Barack Obama en las elecciones presidenciales de 2008 en Estados Unidos (JuvkovaSemova, Requeijo-Rey y Padilla-Castillo, 2017). Desde entonces, se ha conseguido superar la centralidad estratégica del marketing político tradicional.

En España, se entiende que las redes sociales se introdujeron en la comunicación política en las elecciones generales de 2011 (Castillejo y Semova, 2012). Las elecciones generales de 2015 en España estuvieron marcadas por el uso de Twitter por parte de los principales partidos y líderes políticos. Paso a paso, los políticos adaptaron cada vez más sus estrategias comunicativas al entorno digital, otorgándole un peso cada vez más destacado a las redes sociales (Miquel-Segarra, AlonsoMuñoz, y Marcos-García, 2017). Twitter llega a ser la plataforma perfecta para que los actores políticos puedan compartir información sobre sus actividades de campaña respondiendo de inmediato a cualquier asunto que les alude, y que esquivan, así, el cedazo de los periodistas (Enguix, 2017). De hecho, abundantes políticos lo utilizan incluso para transmitir ellos mismos noticias de gran alcance, como hizo este otoño la antaño muy poderosa María Dolores de Cospedal, del PP, al anunciar a través de Twitter que abandonaba irremediablemente su escaño de diputada en el Congreso. Cabría esperar, por tanto, que el uso de Twitter también sea de especial importancia a la hora de tratar políticamente grandes temas de avance e impacto social.

\section{Planteamiento}

Más allá del papel del político como individuo que usa Twitter, está el de las formaciones políticas. La inmersión en Twitter por parte de los partidos políticos implica una adaptación tecnológica, junto a una habilidad discursiva, referida a la presentación y al encuadre informativo/cognitivo (Gallardo, 2014; Gallardo, Enguix y Oleaque, 2018) de los mensajes en la red. Desde este planteamiento, nos interrogamos sobre cómo se desarrolla ese uso especializado en los perfiles de los partidos políticos en Twitter. Nos detenemos en la estructura discursiva de los tuits publicados por las cuentas de PP, PSOE, Ciudadanos, Podemos e IU en la precampaña e inicio de campaña de las elecciones generales del 26 de junio de 2016 (a las que Podemos e IU concurrían juntos). Y nos interrogamos sobre cómo se trata, a través de ellas, uno de los conceptos clave que resultaron de gran importancia en esas elecciones, y que se encuentra, de hecho, unido en muchos aspectos al avance en la innovación que suponen las redes sociales. Se trata del concepto de educación, especialmente sensible ante aquellos comicios por diferentes factores: la implantación de la LOMCE en 2013, la incidencia de la crisis económica sobre los recursos públicos y la larga intensidad de las protestas sociales que derivaron de los dos factores expuestos. De hecho, la educación, como tema, formó parte muy relevante de los programas en todos los partidos ("Comparamos los programas de los partidos políticos de cara al 26J", 2016) y de constantes discursos de la oposición que reclamaban innovación educativa frente a los recortes. Para nuestro artículo, en consecuencia, se han revisado tuits que incluyen el término léxico y temático educación para analizar el significado que se encierra en esos mensajes, dentro del discurso de cada formación política.

A partir de lo expuesto, resumimos las cuestiones principales que nos planteamos: ¿Cuál es la estructura semiótica de los tuits publicados por las cuentas de los partidos?, ¿Hasta qué punto las cuentas de los partidos han desarrollado un discurso propio y diferenciado, y de carácter ciudadano?, y ¿Cómo utilizan esas cuentas un concepto programático de gran relevancia social como es el de educación para llegar a la gente?

\section{Material y método: la estructura discursiva}

Se ha tenido en cuenta para la revisión de la estructura discursiva de los tuits de los partidos, una muestra obtenida a partir de la aplicación twDocs. La exportación de datos se realizó el 14 de junio de 2016, y cubría hasta los últimos 3.200 tuits de cada cuenta.

\begin{tabular}{l|ll} 
PARTIDOS Y NUM. DE TUITS & INICIO & FINAL \\
\hline CIUDADANOS(3.192) & 6 de mayo de 2016 & 14 de junio de 2016 \\
IU (3.200) & 20 de mayo de 2016 & 14 de junio de 2016 \\
PODEMOS (3.199) & 19 de mayo de 2016 & 14 de junio de 2016 \\
PP (3.200) & 27 de abril de 2016 & 14 de junio de 2016 \\
PSOE (3.193) & 30 de mayo de 2016 & 14 de junio de 2016
\end{tabular}

Tabla 1: Detalles de los datos del corpus analizado. 
Oleaque Moreno, J. M. (2018). Perfiles políticos en Twitter: el uso electoral del término educación. @tic revista d'innovació educativa, 21, 23-30.

Fuente: Elaboración propia.

Tras la revisión, se advierten cuatro estructuras posibles de tuit:

Texto; el tuit solo incorpora texto escrito.

Texto + video; texto acompañado de vídeo.

Texto acompañado de una imagen fija.

Texto + url; texto acompañado de enlace.

En cifras globales, el corpus muestra un $54,5 \%$ de tuits de solo texto, y el $45,5 \%$ de tuits con algún tipo de apoyo visual. En cualquier caso, queda claro que el texto escrito juega un papel relevante, pero también se convierte en una realidad la imagen en una red social que, en su origen, basaba su entidad en la sucesión pura y nuclear de mensajes escritos, breves y continuos.

\subsection{La particularidad de los tuits con imagen}

La gestión de las cuentas de Twitter de los partidos, como se ha dicho, da importancia a la imagen, pero la encuadra siempre de algún modo mediante texto; la red social se utiliza con la intención de transmitir mensajes específicos, pero no se confían completamente a la capacidad interpretativa del receptor, sino que, en repetidas ocasiones, se orientan combinando texto e imagen.

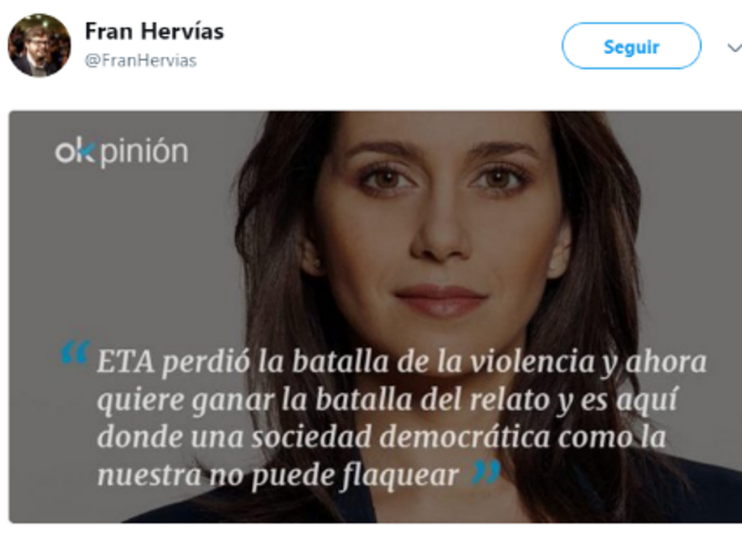

12:36- 23 may. 2016

Figura 1. Tuit del perfil de Ciudadanos. En él, la imagen y el texto se conjugan.

La utilización de la imagen ha ido creciendo progresivamente en las redes sociales, y las cuentas de los partidos políticos participan de esta tendencia. Los medios de comunicación han contribuido a imponerla, y, a su vez, se han visto presionados por la idea, difundida sobre todo por los gestores de Facebook (Enguix 2017), de que el usuario se detiene más en las publicaciones con fotografía. Y aunque el vídeo también está presente, y cada vez más, también los gif, es la imagen fija la que se ha consolidado. Quizás porque la imagen del político se usa como tarjeta de presentación del partido (Castells 2008) en un Twitter donde Usher (2016) entiende las imágenes de los políticos en sus perfiles de redes sociales como micro-celebridades. Esta imagen fija, se divide en la red social en:

1. Texto y fotografía instantánea, compartida en Twitter.

2. Texto e imagen o fotografía editada, que implica algún tipo de elaboración (estilo power point o cartel).

3. Texto e infografía.

Entre todos los tuits que publican texto e imagen fija, los tuits con fotografía son los más habituales para las cinco cuentas, con valores que están entre el $47,5 \%$ del PSOE y el $78,1 \%$ de Ciudadanos.

\subsection{Las funciones discursivas de los tuits}

Revisamos ahora la función discursiva de los mensajes que se publican en cada perfil de partido. Se detectan tres tipos, a los que llamamos: tuits de cita, tuits de agenda y la voz del partido.

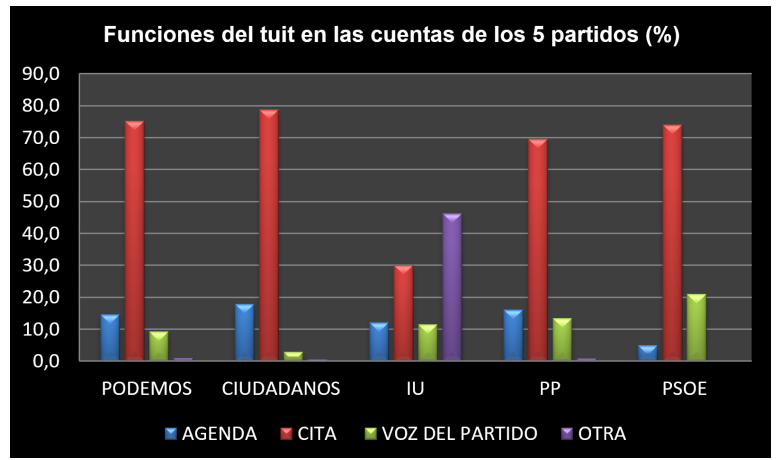

Figura 2: Asignación de funciones a los tuits del corpus. Fuente: Elaboración propia.

Todas las cuentas de los partidos dan protagonismo a la voz de sus líderes. La mayoría lo hacen reproduciendo lo que dicen, mediante los tuits de cita, donde se reproducen fragmentos de sus palabras en actos públicos. Cuando estos tuits se apoyan en la imagen, lo hacen para ilustrar las palabras citadas, o para complementarlas de un modo que amplíe la información. Podemos, Ciudadanos y PSOE dedican a esta función más del $70 \%$ de sus tuits propios. Los tuits de agenda son el segundo gran grupo. Contemplan situaciones referidas, efectivamente, a la agenda de los líderes. Pueden contener un acto que emplaza a los seguidores a determinado acto ("ite esperamos!"), una entrevista al candidato, o una petición del partido. En ocasiones estos mensajes se acompañan con algún reclamo visual. Todas las cuentas utilizan estos tuits de agenda, que describen la actividad prevista para sus líderes y, constantemente, sus apariciones en medios de comunicación.

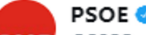

PSOE

Sigue en directo las declaraciones de @AmbBatet en la sede del PSC a partir de las 11h. ¡No te lo pierdas!

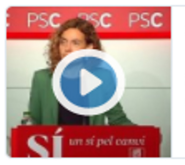

Declaraciones de Meritxell Batet en la sede del PSC La cabeza de lista al Congreso por Barcelona, Meritxell Batet realizará mañana miércoles, día 8 , declaraciones a los medios de ción, en la sede del

$10: 50$ - 8 jun. 2016

Figura 3. Ejemplo de tuit del PSOE con función de agenda.

En tercer lugar, destacan los tuits que introducen la voz del partido. Nos referimos así a los que hablan de medidas políticas sin vincularlas explícitamente a declaraciones de sus líderes; son el grupo menos numeroso, lo que parece indicar que las cuentas no están siendo gestionadas, 
Oleaque Moreno, J. M. (2018). Perfiles políticos en Twitter: el uso electoral del término educación. @tic revista d'innovació educativa, 21, 23-30.

realmente, como perfiles de partido, sino como opción para reproducir todo lo referido a lo que han dicho, o a lo que concierne a sus candidatos. Además, muchos de estos tuits se completan con imágenes de los líderes, lo que distancia de los receptores la imagen del partido como institución, y la reduce a la cara del candidato. El PSOE (21\%) es el partido que más recurre a este tipo de tuits, normalmente vinculados a trazos del programa electoral o a determinadas intenciones.

Por último, una parte mínima de los tuits son tuits propios, que se utilizan con otras funciones. Afectan por encima de todo a IU, con un $46,3 \%$ de tuits propios que desarrollan funciones diversas. Por ejemplo, la función reactiva, dentro de la que publica tuits que interpelan a los seguidores; o la autorreferencial, en la que los tuits hablan de la actividad de gestionar la cuenta (a veces de modo satírico) y en la que cobra protagonismo el equipo community manager de la cuenta.

\subsubsection{Especificidad en cada partido}

Estas diferentes funciones discursivas marcarán el uso político que se hace de Twitter. Así, en la cuenta de Podemos se dedican 318 mensajes a anunciar la agenda de actos (un 9,9\% de los tuits) y 1.634 a citar las palabras de los líderes, sobre todo de Pablo Iglesias (860 menciones). Los mensajes que difunden la voz general del partido son 202 (el 6,3\%). Los siguientes gráficos incluyen también los retuits, una forma de función subordinada, que suelen ser de la cuenta propia de los líderes de los partidos.

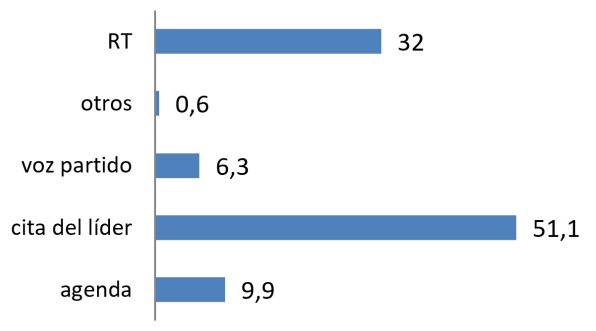

Figura 4. Funciones de los tuits en la cuenta de Podemos; se incluye también el \% de retuits (RT).

Fuente: Elaboración propia.

Respecto al resto de formaciones, lo más evidente de la cuenta de Ciudadanos es su concepción exclusiva del perfil de Twitter como altavoz del líder, con un amplísimo protagonismo de Albert Rivera, al que se dedican un $55,5 \%$ de los tuits, ya sea como sujeto emisor (tuits de cita, sobre todo) o como protagonista de la política (tuits de agenda). Sin embargo, no hay apenas mensajes en los que quepa reconocer una voz de partido. De hecho, el $14 \%$ de los retuits son de la cuenta de Albert Rivera, con lo que la identificación del partido con la voz directa de su líder es clara y relevante.

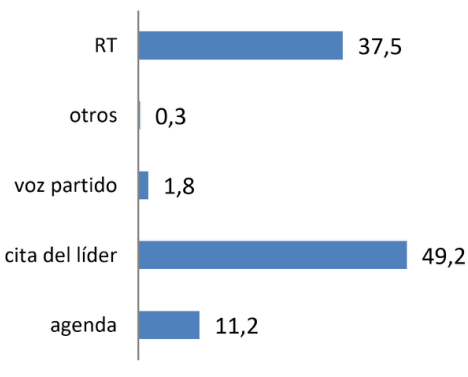

Figura 5. Funciones de tuits en la cuenta de Ciudadanos; se incluye también el \% de retuits (RT).

Fuente: Elaboración propia.

En la cuenta del PP, la función predominante es la de reproducir citas de los líderes políticos del partido y dar cuenta de sus agendas electorales. Como ocurre con la cuenta de Ciudadanos, gran parte de los retuits (un 21\%) se concentra en la cuenta personal de Mariano Rajoy.

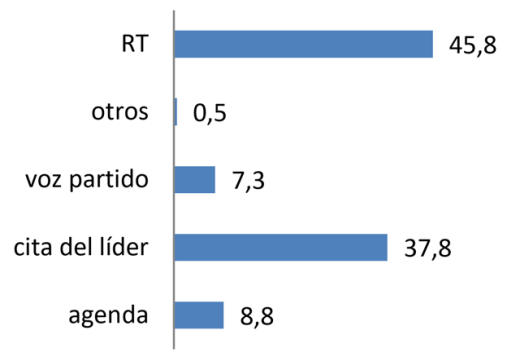

Figura 6. Funciones de los tuits en la cuenta del PP; se incluye también el \% de retuits (RT).

Fuente: Elaboración propia.

EI PSOE rentabiliza los eslóganes de campaña para introducir en los tuits la voz del partido, consolidándose como una cuenta que no solo traslada mensajes de líderes concretos. De ahí que sea el perfil que más tuits dedica la difusión de aspectos de su programa (13,2\%). Como ocurre con el PP, hay abundantes tuits que enlazan a la web propia para ampliar información.

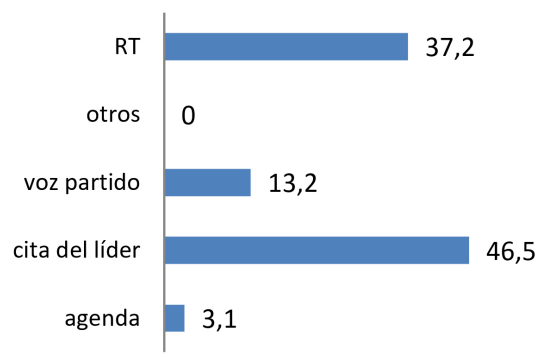

Figura 7. Funciones de los tuits en la cuenta del PSOE; se incluye también el \% de retuits (RT).

Fuente: Elaboración propia.

Por último, la cuenta de IU Ilama la atención por la gran cantidad de tuits que, como se ha dicho, se dedican a las funciones de frivolización como estrategia apelativa para el seguidor; la utilización como transmisión de las citas del líder se reduce al mínimo del corpus (un 17,3\% de los tuits, frente al máximo del 51,5\% en Podemos). No quiere 
decir, sin embargo, que no exista el personalismo en torno a la figura de Alberto Garzón, sino que se explota de otras maneras, convirtiéndolo en protagonista de los mensajes, sean cuales sean. Esto se explica, como ya se ha adelantado, con otro rasgo característico del perfil de IU, y es el protagonismo del equipo community manager de la cuenta. En esta estrategia, el léxico marcado impone un sesgo de edad que, si bien puede tener efectos excluyentes, lo apuesta todo hacia un sector que simpatice con un estilo supuestamente rebelde y juvenil, dando por supuesta la coincidencia ideológica. Este rasgo se ajusta con las conclusiones de Gallardo (2017) sobre la ausencia general de una proclama ideológica abierta como parte de muchos mensajes políticos a los seguidores de Twitter.

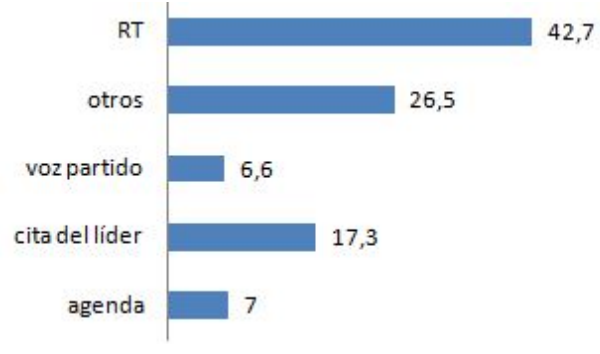

Figura 8. Funciones de los tuits en la cuenta de IU; se incluye también el \% de retuits (RT). Elaboración propia.

\section{Análisis y resultados en torno al uso del término educación}

Una vez definidos los diferentes aspectos de la estructura discursiva de los tuits en cada cuenta, analizamos, tal como se ha definido en el planteamiento de este estudio, el comportamiento a través de las mismas del término educación. Para ello, en primer lugar, detectamos de entre el total del corpus, el conjunto de tuits en los que se utiliza el referido término. Esto reduce el corpus específico a 339 tuits. Esta reducción del corpus resulta muy llamativa, tanto por la importancia y actualidad de la educación como campo temático, como por todo lo que envolvía los recortes económicos públicos que la afectaban y por las necesidades de inversión ligadas a innovación en este ámbito. Sin embargo, el reflejo de todo ello en Twitter es muy inferior a lo que podía esperarse en una precampaña o inicio de campaña electoral. EI PSOE es el partido que más mensajes emite sobre este ámbito, con 178 tuits. Le sigue Ciudadanos (77), PP (56), y, con igual número, Podemos e IU (14 cada formación, que mantienen su especificidad en Twitter pese a la candidatura Unidos Podemos).

Ocasionalmente se da uso de la imagen en los referidos tuits. En el PSOE se da en 53 casos, predominando la variante formal del texto más vídeo. En el PP, en 28 casos, con predominio también del vídeo. En Ciudadanos, en 23 ocasiones, con uso del texto más fotografía (incluyendo como parte el formato cartel). En Podemos, en 10 casos, con predominio del texto más fotografía fija. Y lo mismo para IU, con 5 casos. Pero el dominio claro en este corpus específico dedicado a la educación es el del uso eminente y sencillo del texto, o de texto más enlace, algo que sugiere poca inversión, o poco esfuerzo, en la elaboración formal de los tuits dedicados al ámbito educativo.

Para entender los significados que predominan en los usos de educación, seleccionaremos una muestra de cuatro tuits aleatorios (emitidos entre el 1 y el 14 de junio) de cada perfil (20 tuits en total, combinando tuits de texto con tuits que también utilicen imagen). Sobre ellos plantearemos un análisis cualitativo más detenido. En él, profundizaremos en las creencias que subyacen tras la apariencia de los tuits. Lo haremos dentro del marco del análisis crítico del discurso (ACD) para comprobar qué significados hay enterrados bajo la superficie textual. El ACD es un enfoque crítico, que tiene en cuenta la importancia del contexto social, y político, aparte del periodístico. En su base está el estudio de la ideología (de las creencias de un grupo) como forma de influencia y voluntad de dominio. EI ACD no compone una teoría, sino un movimiento internacional de investigación, que ha buscado desvelar, a través de enfoques variados, la reproducción discursiva del poder (o de la intención de tenerlo, o de aplicarlo), y del uso del lenguaje como forma del mismo (Reisigl y Wodak, 2015). En nuestro caso, dentro del ACD, para revisar qué hay oculto tras el uso superficial de educación como concepto, llevaremos a cabo la aplicación de aspectos determinados del llamado encuadre ideológico, impulsado por Van Dijk (2003), un enfoque que intenta mostrar las creencias e intenciones sociales y políticas que subyacen en los discursos (algo especialmente intrincado en el uso político de Twitter, dada su eventual tendencia a esquivar una apariencia ideológica evidente).

Utilizaremos para ello dos grandes categorías que resultan habituales en este encuadre: la primera, la autopresentación positiva de nosotros y la presentación negativa de los otros; y la segunda, el recurso a la suposición. La primera consiste en legitimar o deslegitimar los intereses de uno u otro grupo, basándose en hablar o escribir de nuestros aspectos positivos (es decir, los del grupo emisor del mensaje) y de sus aspectos negativos (los de los rivales o competidores). Esta estrategia se refuerza de diferentes maneras, como con el hecho de no hablar de nuestros aspectos negativos o de no hablar de sus aspectos positivos. Es decir, de poner o de quitar énfasis en aquello que interesa al grupo emisor.

En cuanto a la suposición, es un tipo específico de implicación semántica que se toma por cierta tanto si lo que se plantea es verdadero como si no (Machin y Mayr, 2012). De hecho, de esta forma indirecta se afirman proposiciones cuya veracidad se da por supuesta. Es el caso de todas las formas de conocimiento compartido o de fundamento común, un cuerpo de conocimiento que puede incluir abundantes estereotipos socio-culturales, que nunca se cuestionan, y que se presuponen en la interacción y el discurso diarios. No determinamos en la aplicación de nuestro análisis la carga de intencionalidad que pueda haber en la transmisión de significados a través de estos recursos, puesto que no es relevante a la hora de establecer si los discursos pueden ser, por ejemplo, discriminatorios (Van Dijk, 2002; 2003). Su aplicación la concretaremos en una serie de ejemplos que numeraremos dentro de los apartados que siguen a continuación.

\subsection{La auto-presentación positiva y la presentación negativa de los otros}

En todos los perfiles aparece regularmente el recurso a la auto-presentación positiva y, sobre todo en los partidos de izquierda, la presentación negativa de los otros. El primer ejemplo, es de un tuit del PSOE: 
Oleaque Moreno, J. M. (2018). Perfiles políticos en Twitter: el uso electoral del término educación. @tic revista d'innovació educativa, 21, 23-30.

1. “Lo decimos muy claro: sanidad y educación públicas, universales, gratuitas y sin \#copago",

En él, la visión positiva de nosotros apunta a qué sucederá si gobiernan los socialistas (universalización de la educación, etc.); la presentación negativa del rival (PP) se concreta, de manera más sutil e indirecta, en la referencia directa al copago farmacéutico instaurado por Rajoy, que implica también una política de recortes, y de involución, en la educación.

Por contra, el PP, consolidará la auto-presentación positiva sin sugerir presentaciones negativas de sus contrincantes, en lo que parece ser una estrategia de no contestar ataques para no buscarse más complicaciones (el Gobierno estaba muy afectado por la corrupción, el desgaste, y la mala prensa), y generar, al mismo tiempo, una imagen de gobernantes solemnes. Se muestra en el siguiente tuit del partido conservador:

2.“Hemos preservado el Estado del Bienestar. Con más y mejor empleo, fortaleceremos la sanidad y la educación públicas".

La auto-presentación se concreta en una primera frase que defiende aquello que supuestamente se ha hecho, para profundizar luego en lo que el PP hará si recibe el apoyo electoral. Se trata, por tanto, de una exposición de la auto-legitimación a costa del uso de la educación, y de todo lo que sugiere: un concepto que siempre va a aparecer como parte clave en los tuits que analizamos, pero sin una explicación añadida de lo que se va a hacer para potenciar su mejora, su innovación o su avance, más allá de lemas o deseos de aroma propagandístico.

La actitud de Ciudadanos, por su parte, se asemejará a la del PP, pero adaptándola a su particularidad como partido neo-conservador de aspiración regeneracionista, que sin haber estado en el poder real, se auto-erige lejos de su contaminación, mostrándose especialmente práctico. Se advierte en el siguiente tuit:

3."En C's apostamos por vincular la economía a la educación y al conocimiento".

En él, como algo positivo de la perspectiva del partido, se rinde culto a la economía como medida práctica del funcionamiento de las grandes materias sensibles de cualquier gobierno, como lo es la educativa. Se hace, pese a que es la economía la que ha marcado todos los recortes en este campo que se han acometido desde el inicio de la crisis en la segunda mitad de la década de 2000. Para ofrecer importancia a esta reflexión dentro del tuit, Ciudadanos acompaña el texto con una imagen fija, que se muestra tras estas líneas. Una fotografía que refuerza esa auto-presentación positiva con la instantánea de un acto público en la que el líder del partido, Albert Rivera, ofrece una imagen cercana (en mangas de camisa), aunque con gesto serio, comprometido, como plasmación de lo que se quiere transmitir del partido,
@ Albert Rivera "En C's apostamos por vincular la econolmía a la educación y al conocimiento" \#ActualidadCs

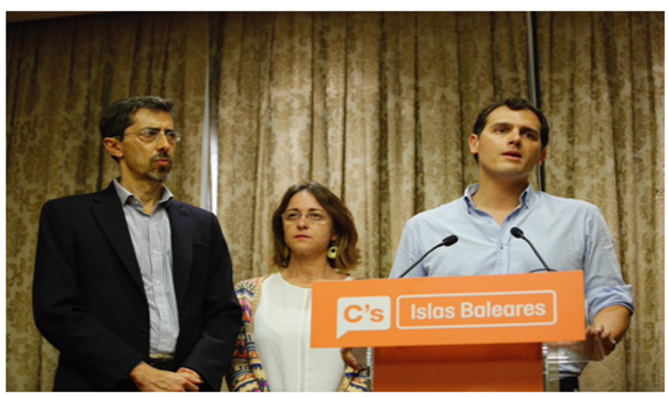

Figura 9. Tuit de Ciudadanos, que reproduce palabras de Albert Rivera.

Podemos, a continuación, erigirá una auto-presentación positiva que no se acompaña con ningún tipo de presentación negativa de otras formaciones rivales:

4. "Mediante la recuperación de empleo en educación y sanidad queremos generar un efecto multiplicador en la economía".

Pero IU, sin embargo, hará lo contrario: basará su autopresentación positiva en el sufrimiento. Es decir, en una presentación muy negativa de los gobernantes en el poder, auto-presentándose como parte de aquellos que han padecido intensamente las consecuencias de esas políticas negativas.

5. "Sufrimos la despoblación porque se han cargado nuestro futuro, nuestra sanidad, nuestra educación".

En este caso, pesa una contraposición verbal. La observamos en el contraste entre sufrimos, que hace referencia a que en la formación política está viviendo el dolor, y se han cargado, una acción que indica que otros (el poder que gobernaba España, el PP, aunque no se le nombra directamente) les están causando ese dolor. Nuestra educación, queda, pues, en un vehículo para orquestar la auto-presentación de modo muy impactante, en vez de en un elemento que pueda ayudar a entender las políticas reales que se tengan previstas si se ganan las elecciones. Algo que también se ha producido, aunque de manera menos contundente, en los otros casos expuestos.

\subsection{La estrategia discursiva de la suposición}

Revisamos ahora la estrategia discursiva de la suposición. A través de ella, la referencia a la materia educativa va a ser también un canalizador para reforzar i intenciones de los partidos sobre sus seguidores a través de Twitter. Es así en el siguiente tuit del PSOE:

6. "Vamos a universalizar la educación de 0 a 18 años\#UnSíPorLaEducación".

En él se da por supuesto que la educación hasta la mayoría de edad no es universal en España; y también, que el Gobierno del PP representa lo contrario a ello: la negativa a que esa educación universal se produzca, lo 
contrario a lo que se presenta como un derecho para todos. Esto último queda, según la suposición, directamente en manos de que el PSOE llegue a gobernar en España. La suposición también influye en lo contrario del hastag que utilizan los socialistas: sugiere que el PP es un No por la Educación, ya que el PSOE representa plenamente el Sí.

EI PP, no obstante, ofrecerá un punto de vista propio con otro tuit:

7."Hay que innovar en educación para adaptarse a las nuevas profesiones".

El uso de la suposición empuja ahora hacia un significado latente: el de que las muy criticadas reformas educativas llevadas a cabo por el PP se han realizado en realidad por el bien de todos como innovación para adaptarse al mercado. Con lo que se infiere que aquellos que las han criticado están en contra de la adaptación a esas nuevas profesiones, y están, por tanto, perjudicando a la sociedad. Como era previsible, en todo ello no se especifica nada sobre esas profesiones ni sobre cómo debe innovarse. Como tampoco en el anterior tuit del PSOE se concretaba de qué modo se iba a llevar a cabo la misión de universalizar. El resultado es que el usuario de Twitter recibe intenciones de los partidos políticos, pero no los pasos ni explicaciones para llevarlas adelante. Si bien la capa superficial de los tuits, por tanto, parece podada de voluntad política determinada, esa ideología, sin embargo, mantiene su pálpito en el significado interno, envuelta por el recurso a las suposiciones.

Se advierte también en los mensajes de Ciudadanos, como el del siguiente tuit:

8."Es intolerable que en España se esté haciendo un debate partidista sobre la educación".

El partido de Rivera descalifica lo que hacen otros, sin precisar quiénes son, cómo lo hacen ni qué hacen en realidad. La suposición encadenada es que, si gobierna Ciudadanos, Rivera parará algo que está resultando intolerable. Este recurso transmite un significado que revierte en el habitual discurso de este partido: la ubicación constante en una especie de centro político puro que (supuestamente) lo aleja de tendencias partidistas clásicas.

Finalmente, se dará una particularidad en las dos fuerzas políticas restantes de nuestro análisis, que concurrían juntas a la cita electoral. Tanto IU como Podemos utilizan la suposición, pero, en este caso de un modo esencialmente más auto-legitimador propio, que deslegitimador del resto. Se observa en este tuit de IU:

9.“Representante marea verde defiende la escuela pública en \#Asamblea IU garantizando la educación constitucionalmente".

El tuit está acompañado de una fotografía en blanco y negro, con un mensaje, insertado en la imagen: "construimos izquierda". Ese lema, de hecho, refuerza la suposición de que la marea verde (el movimiento de protesta a favor de la escuela pública) sólo tiene sentido con la izquierda, y que ésta, a su vez, es IU. Por tanto, la conexión de suposiciones deriva en que IU garantiza la educación de modo constitucional, por encima de cualquier otro partido.
De modo similar lo aplicará Podemos en el tuit que se observa en el siguiente tuit:

10."Sanidad y educación son derechos fundamentales para todo ser humano que asientan el futuro de un país. \#Debate13J"

La suposición permite inferir, lógicamente, y de manera reflexiva, que Podemos sí considera estas materias como derechos fundamentales, destacando en esto, al manifestarlo tan abiertamente, por encima del resto de formaciones. Se infiere también que, con ello, va a ayudar a asentar el futuro de España. Una suposición ética y patriótica que contradice los constantes ataques contra esta formación, que la presentan como parte de una izquierda radical y anti-sistema. Este mensaje expande, la idea contraria. De hecho, como puede verse a continuación, en la imagen editada que complementa el tuit, hasta la fotografía del líder Pablo Iglesias es amigable, y parece dar la bienvenida de manera constructiva a ese futuro del que habla el tuit.
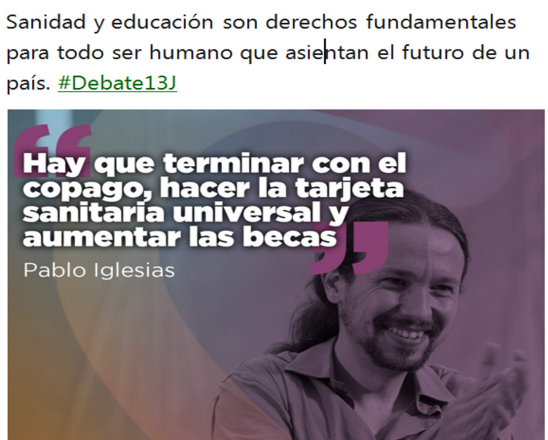

Figura 10. Tuit del perfil de Podemos, con Pablo Iglesias como imagen.

Con ello, utilizando el concepto clave de la educación, se transmite una creencia interesada. La cual, como en otros ejemplos antes vistos, empuja hacia la transmisión de un concepto ideológico y político determinados, en busca de un camino triunfante en las inminentes elecciones. Pero, una vez más, no aparecen indicaciones de cómo hacer avanzar el campo educativo y su innovación o de cómo tratar las cuestiones complejas que lo han venido afectando.

\section{Conclusiones}

Tras haber estudiado el uso de Twitter en las cuentas de cinco partidos políticos españoles presentes en la campaña electoral de 2016, y el uso en ellas de 'educación' como léxico destacado, una de las conclusiones respecto a su funcionalidad, es que estas cuentas replican las palabras de los líderes políticos. La revisión de tuits muestra que las cuentas de las formaciones políticas en Twitter no evidencian un uso realmente institucional, o social, sino que se ponen al servicio de la personalización, cediendo la voz (de manera directa, o rindiéndoles tributo) a los líderes, empezando por los candidatos. La excepción eventual es el PSOE, cuya cuenta da más protagonismo a la voz del partido, al punto de vista institucional expresado de manera también institucional. No obstante, y pese a ciertos matices, en general se revela una poca profesionalización del manejo de las redes sociales en las cuentas de los partidos, ya 
que no son, en muchas ocasiones, una fuente emisora primaria, sino que aparece subordinada a los mensajes calcados estrictamente de sus líderes.

Dentro de la estructura formal de los mensajes, en los que abunda el formato-texto esencial, se detectan pocas variantes también cuando se da el eventual uso de imagen, ya que es mucho más lo que las cuentas tienen en común. Es en este contexto de similitudes en el que el concepto relativo a la educación se repite una y otra vez. Pero no aparece desarrollado en forma de explicación del papel que puede cumplir como tema clave, en el programa electoral: la aplicación que hemos llevado a cabo del llamado encuadre ideológico, dentro del ACD, ha demostrado que su uso es predominantemente como vehículo, o como canal, para hacer llegar al usuario de Twitter determinados efectos textuales, deseos políticos, o proclamas variadas.

En este sentido, los partidos eluden explicar el compromiso que puedan tener con el ámbito educativo, al que sólo muestran consideración para generar un mensaje con intencionalidad electoral evidente, y no necesariamente relacionado con lo que significa ese concepto, ni con su mejora o innovación. De hecho, el análisis realizado nos indica que las ideologías de los partidos, en tanto a creencias sociales y políticas, se mueven bajo las estructuras formales de los tuits, transmitiendo significados subyacentes que interesan a los partidos que las emiten. Twitter pierde, con ello, el uso informativo característico que tuvo en sus inicios. $Y$ educación se consolida simplemente como un anexo conceptual de determinadas transmisiones de significado. Transmisiones que pueden acabar teniendo formas no esperadas, con partidos que pueden no deslegitimar de manera directa o totalmente clara a sus contrincantes sino que eventualmente se refuerzan a ellos mismos con auto-presentación positiva muy trabajada. Pero que, en suma, parecen más conectados en el uso de Twitter a la expansión constante de tradicionales efectos propagandísticos, que a los actos de mejora plausible de la educación como interés público y materia de futuro para innovar en aras del bien social.

\section{Bibliografía}

Castells, M. (2008): Comunicación, poder y contrapoder en la sociedad red (I). Los medios y la política, Telos, 74. Recuperado de https://telos.fundaciontelefonica.com/archivo/nume ro074/

Castillejo, B., y Semova, D. (2012). Elecciones Generales y redes sociales en el caso de España, 2011, International Review of Information Ethics, 18(12), 144-149. Recuperado de http://www.i-r-ie.net/inhalt/018/Castillejo-Semova.pdf

Comparamos los programas de los partidos políticos de cara al 26J (21 de junio de 2016). Los Replicantes. Recuperado de https://www.losreplicantes.com/articulos/programapartidos-politicos-26j

Dader, J. L. (2017). Campañas políticas 'online': la realidad española frente al horizonte internacional del 'tecnocabildeo', en J.L. Dader y E. Campos (Coords): La búsqueda digital del voto.
Cibercampañas electorales en España 2015-2016. València: Tirant Lo Blanch, 11-73.

Enguix Oliver, S. (2017). Impacto político e informativo de las redes sociales: esferas de actuación y comparación con los médios, Anàlisi. Quaderns de Comunicació i Cultura, 56, 71-85. https://doi.org/10.5565/rev/analisi.3090

Gallardo Paúls, B. (2014). Usos políticos del lenguaje. Un discurso paradójico. Barcelona: Anthropos/Siglo XXI.

Gallardo Paúls, B (2017): Pseudopolítica en la red: indicadores discursivos de desideologización en Twitter, Pragmalingüística, 25, 189-210. https://doi.org/10.25267/Pragmalinguistica.

Gallardo Paúls, B., Enguix Oliver. S, y Oleaque Moreno, J.M (2018). Estilos de gestión de los perfiles políticos en Twitter: imagen y texto en las cuentas de los partidos en la campaña del 26J, Revista de investigación lingüística, 21 (en prensa).

Jivkova-Semova, D., Requeijo-Rey, P. y PadillaCastillo, G. (2017). Usos y tendencias de Twitter en la campaña a elecciones generales españolas del 20D de 2015: hashtags que fueron trending topic, El profesional de la información, 21(5), 824-837. https://doi.org/10.3145/epi.2017.sep.05 .

Machin, D. y Mayr, A. (2012). How to do Critical Discourse Analysis. London, Thousand Oaks, New Delhi, Singapore: Sage.

Miguel-Segarra, S., Alonso-Muñoz, L. y MarcosGarcía, S. (2017). Buscando la interacción de partidos y candidatos en Twitter durante las elecciones generales de 2015, Prisma Social, junionoviembre. Recuperado de http://www.redalyc.org/articulo.oa?id=3537518200 02

Reisigl, M. yWodak, R (2015). The discourse historical approach (DHA), en R.Wodak y M. Meyer. (Eds). Methods of Critical Discourse Studies. Third Edition. London, Thousand Oaks, New Delhi, Singapore: Sage, 23-61

Usher, B. (2016). ME, YOU, And US: Constructing political persona on social networks during the 2015 UK General Election. Persona Studies, 2(2), 19-41. https://doi.org/10.21153/ps2016vol2no2art608.

Van Dijk, T. A. (2002). Discurso y racismo. Persona y Sociedad, 16(3), 191-205. Recuperado de http://www.discursos.org/oldarticles/Discurso\%20y \%20racismo.pdf

Van Dijk, T.A. (2003). Ideología y discurso. Barcelona: Ariel. 
Oleaque Moreno, J. M. (2018). Perfiles políticos en Twitter: el uso electoral del término educación. @tic revista d'innovació educativa, 21, 23-30.

| Cita recomendada de este artículo

Oleaque Moreno, J. M. (2018). Perfiles políticos en Twitter: el uso electoral del término educación. @tic revista d'innovació educativa, 21, 23-30. https://doi.org/10.7203/attic.21.13429 